\title{
Reducing Recidivism and Symptoms in Emerging Adults with Serious Mental Health Conditions and Justice System Involvement
}

\author{
Maryann Davis, PhD, \\ Center for Learning and Working During the Transition to Adulthood, Center for Mental Health \\ Services Research, Department of Psychiatry, University of Massachusetts Medical School \\ Ashli J. Sheidow, PhD, and \\ Family Services Research Center, Department of Psychiatry and Behavioral Sciences, and \\ Department of Pediatrics, Medical University of South Carolina

\section{Michael R. McCart, PhD} \\ Family Services Research Center, Department of Psychiatry and Behavioral Sciences, and \\ Department of Pediatrics, Medical University of South Carolina
}

\begin{abstract}
The peak years of offending in the general population and among those with serious mental health conditions (SMHC) are during emerging adulthood. There currently are no evidence-based interventions for reducing offending behavior among 18-21 year olds, with or without SMHC. This open trial examined outcomes from an adaptation of Multisystemic Therapy (MST), an effective juvenile recidivism reduction intervention, modified for use with emerging adults with SMHC and recent justice system involvement. MST for emerging adults (MST-EA) targets MH symptoms, recidivism, problem substance use, and young adult functional capacities. All study participants $(\mathrm{n}=41)$ were aged 17-20 and had a MH diagnosis and recent arrest or incarceration. Implementation outcomes indicated that MST-EA was delivered with strong fidelity, client satisfaction was high, and the majority of participants successfully completed the intervention. Research retention rates also were high. Pre-post analyses revealed significant reductions in participants' MH symptoms, justice-system involvement, and associations with antisocial peers.
\end{abstract}

\section{Introduction}

Adolescence and emerging adulthood are the age periods of peak offending in the general population $^{1-3}$ as well as among individuals with serious mental health conditions $\left(\mathrm{SMHC} ;{ }^{4}\right)$. "Emerging adulthood" will be used herein to refer to ages 17-25 unless otherwise noted. ${ }^{5}$ Compounding this, individuals with SMHC have greater justice system involvement than those without SMHC, both as juveniles ${ }^{6-8}$ and emerging adults. ${ }^{6,9,10}$ For those with intensive adolescent mental health service use, the majority will be arrested by

Address correspondence to Maryann Davis, PhD, Department of Psychiatry, University of Massachusetts Medical School, 55 Lake Avenue, Worcester, MA 01655, USA. Phone: 508856 8718; Fax: 508856 8700; Maryann.Davis@ umassmed.edu. 
their mid-20's. ${ }^{11-14}$ Further, among emerging adults with SMHC, those with recent justice system involvement are at greatest risk for arrests. Indeed, data indicate that among recently arrested emerging adults with SMHC, re-arrest rates peak at 50\% for men and 39\% for women. ${ }^{14}$ Justice system involvement can be a strong impediment to positive development. It is a strong predictor of school dropout, ${ }^{15,16}$ unemployment, ${ }^{17-19}$ low earnings, ${ }^{18-20}$ welfare dependence, ${ }^{17}$ and substance abuse problems ${ }^{17,21}$ in young adulthood. Thus, reducing recidivism in this high risk group with SMHC, during the ages when offending becomes criminal rather than delinquent, might significantly modify adult trajectories of offending and support more positive developmental outcomes. ${ }^{22}$

Yet, there are no established interventions with evidence of efficacy to reduce recidivism among emerging adults with or without SMHC. There are evidence-based interventions to reduce offending and re-offending in juveniles in the general population, including Multisystemic Therapy ${ }^{23}$ and Multidimensional Treatment Foster Care, ${ }^{24}$ but these services have not been used or evaluated with individuals older than 17 years of age. ${ }^{25}$ Evidencebased practices for reducing recidivism in the adult general population include substance abuse treatment, ${ }^{26}$ education ${ }^{27}$ or employment ${ }^{28,29}$ programs, and the general array of cognitive behavioral approaches for reducing offending behavior. ${ }^{30,31}$ All have moderate effects on recidivism, but the efficacy of these approaches specifically with emerging adults is either unknown or less potent. ${ }^{32}$ Only two programs with a focus on emerging adults have some evidence of recidivism reduction efficacy in the general population. Both programs delivered developmentally appropriate supports (e.g., attending to housing, vocational, or educational needs) for justice system-involved emerging adults in the community. ${ }^{33,34}$ Though limited in their research design, in each study the specialized intervention group had better recidivism outcomes than the control group, highlighting the potential utility of targeting emerging adults' unique developmental challenges in the context of recidivism reduction approaches. ${ }^{33,34}$

Though there is debate about whether treatment of SMHC contributes to reduced recidivism (e.g. ${ }^{35-37}$ ), there is little debate about the appropriateness of ensuring that offenders with SMHC receive good MH treatment as part of pre- or post-plea court diversion, ${ }^{38,39}$ or as part of justice system community supervision..$^{40}$ Further, malleable risk factors for offending among those with SMHC are similar to those in the general population including school failure, ${ }^{41-45}$ alcohol and substance use, ${ }^{41-47}$ unemployment, ${ }^{46}$ poverty, ${ }^{36}$ and homelessness. ${ }^{48,49}$ Thus, recidivism reduction approaches for emerging adults with SMHC should include provision of good mental health care and approaches to reduce recidivism that address the changing nature of recidivism correlates during the transition from adolescence to mature adulthood.

As youth mature, some of the factors that cause delinquent behavior dissipate or evolve into adult versions of those causes. For example, parents no longer exert a direct supervisory and monitoring role (e.g., ${ }^{50,51}$ ) during emerging adulthood, but families continue to provide important resources (e.g., work in family business or with family friends), emotional support (e.g., encourage staying out of trouble), and a safety net (e.g., move back home when selfsupport fails). ${ }^{52-54}$ Similarly, structured time (e.g., ${ }^{55}$ ) shifts from attending school to working. The role of antisocial peers (e.g. $\left.{ }^{56}\right)$ remains, ${ }^{57-61}$ but diminishes as the daily 
social environment shifts from high schools to smaller workplaces, and romantic relationships increasingly include marriage and parenting (e.g.. ${ }^{22,62}$ ). Other factors contribute to recidivism in adolescents and adults, and therefore, should be the target of recidivism reduction approaches in emerging adults: rational choice (i.e., how individuals weigh costs and benefits of potential behavior and act on their conclusions ${ }^{63-66}$ ) and substance abuse (e.g., $\left.{ }^{1,67-69}\right)$.

Given the high risk of recidivism in emerging adults with SMHC, the negative impact of justice system involvement on positive development, and the absence of any approach with strong evidence of recidivism reduction efficacy in this age group, an intervention that reduces the risk of recidivism in emerging adults with SMHC would be of great value. An important first step towards achieving this goal is developing a community-based (i.e., noninstitutional) model that prevents re-offending. A community-based model can assist offenders in a wide array of circumstances: those on community-based sanctions (e.g., probation, parole), those re-entering after incarceration, those arrested but not convicted (but at heightened risk of re-offending), and those qualifying for an alternative to incarceration. A community-based model also emphasizes service provision in the least restrictive environment. ${ }^{70}$

Multisystemic Therapy (MST) is a manualized, community- and family-based intervention with proven effectiveness for reducing recidivism in delinquent youth aged 12-17 (e.g., ${ }^{71-75}$ ). The standard MST model has not been used with emerging adults or with individuals experiencing significant MH concerns. The current paper, however, describes an adaptation of MST for emerging adults (MST-EA) who are (a) between the ages of 17 and 21, (b) have an SMHC and recent arrest or release from incarceration, and (c) residing in the community. In addition, the paper presents feasibility findings based on an open pilot trial of the MST-EA approach.

Positive youth development approaches support youths' strengths and facilitate the growth of attributes that mark a flourishing, healthy young person (e.g. ${ }^{76-79}$ ) in the context of multiple relationships as described in relational developmental systems theoretical models. ${ }^{80}$ MST is a positive youth development approach that is based on social ecological theory, ${ }^{81}$ and emphasizes that youth are imbedded in multiple interconnected systems (i.e. family, extended family, neighborhood, school, peers, and community). MST treatment principles emphasize approaches that are positive and build on youths' strengths.

In order to describe the adaptations to MST that were incorporated in MST-EA, a brief description of standard MST is provided. ${ }^{82}$ MST is a home-based intervention for antisocial youth aged 12-17. It employs a team of 3-4 master's level therapists, each carrying a caseload of 4-6 families, overseen by an on-site clinical supervisor. An intensive training and quality assurance system is used, which includes an off-site MST expert who conducts weekly telephone consultation and quarterly booster trainings with the team. MST promotes behavioral change by empowering caregivers/parents to make changes in the ecology of the juvenile. Specifically, the MST therapist and caregiver/parent work together to target a comprehensive set of risk factors across individual, family, peer, school, and neighborhood domains. Interventions integrate empirically-based clinical techniques, primarily from the 
cognitive and behavioral therapies. The intervention is fairly intensive, with typically 2 or more sessions per week with families, flexible scheduling including evenings and weekends, and 24/7 availability of MST team members to help manage behavioral crises and prevent out-of-home placements.

The MST-EA adaptation addresses factors that are the most likely causes of offending and poor mental health in emerging adults with both criminal justice involvement and an SMHC. Further, the adapted model has been made developmentally appropriate for 17-21 year olds via individualized interventions and support from age appropriate social agents (i.e., social network members and a Coach). The primary goals of MST-EA are to reduce recidivism and support positive functioning in school, work, independent living, and relationships (including parenting skills, when needed), while ensuring treatment and management of mental illness and any co-occurring substance use disorder. Such a focus on emerging adults' functional growth and relationships is consistent with the emphases of positive youth development approaches. ${ }^{79}$

MST-EA was designed for the youngest emerging adults (17-21 year olds) because (a) this age group has the highest rates of offending, (b) this age group allows for an important first extension of the model into adulthood beyond that served by standard MST (up to age 17), (c) this reflects ages in which child/juvenile justice services end and adult/criminal justice services begin (usually between ages $18-21^{9,80}$ ), and (d) the ending of child and beginning of adult services at this age range is associated with both loss of health care coverage c $^{83,84}$ and reduction in mental health service utilization (e.g. ${ }^{85}$ ). MST-EA follows the MST treatment principles and process, ${ }^{86}$ but the two most significant adaptations are that the client (i.e., the emerging adult) is the primary lever for change instead of the caregiver/ parent, and the role of "family" is expanded to include the emerging adult's "social network". The social network can include biological, extended, or foster family, as well as close friends, significant others, or adult allies. The therapist completes a social network analysis ${ }^{87}$ to "map" each EA's social network and identify ways each social network member could be helpful to supporting the client's goals. The MST-EA team works in partnership with the client to determine goals and steps to achieve those goals, with the client guiding decisions about how to include the social network to support his goals. MSTEA therapists also utilize the full array of Motivational Interviewing strategies to engage clients in the intervention, ${ }^{88}$ in addition to the strategies all MST models utilize to overcome engagement and retention barriers (e.g., flexible scheduling, home-based services, targeting practical barriers, strength-focused approach).

Because MST-EA therapists deliver a broader array of treatments than standard MST therapists (i.e., intensive mental health and substance abuse treatment), and because of the high risk for criminal recidivism and mental health crises in the MST-EA population, caseloads are reduced to no more than four clients. Specific mental health and substance abuse treatment approaches fall within the array of cognitive and behavioral therapies (e.g. Behavioral Activation, Prolonged Exposure, Contingency Management). Therapists deliver intensive interventions ( 3 or more sessions plus phone contact each week) with the 24/7 crisis management availability and flexible scheduling that MST is known for providing. Given the high risk for suicidality, homicidality, and victimization among this population, 
extensive effort is devoted to ensuring safety of the client and the client's social network members, with continuous assessment and safety planning from the very start of the intervention.

The MST-EA adaptation added part-time psychiatric support to the team, to ensure rapid access to psychiatric care when needed. The adaptation also added four part-time Coaches that are paraprofessional positions. The Coaching approach incorporates general mentoring features that have good evidence of efficacy and are consistent with the MST-EA intervention. It is field based mentoring, ${ }^{89}$ occurring in the homes and communities of MSTEA clients. It is a cross-age peer mentoring approach, ${ }^{90}$ in which slightly older emerging adults (without disabilities) provide instrumental mentoring ${ }^{91}$ that is both relationship and transition skill-focused. The skill component targets skills that are newly developing in emerging adulthood (e.g. finding appropriate housing, identifying and applying for jobs, setting and achieving goals, managing money and a household, staying healthy). The Coach curriculum covers a total of 13 domains, and each domain includes curriculum for 3-7 sessions. Sessions contain information, exercises, and activities. Coaches generally meet with clients twice a week, with part of one visit focused on the transition skill curriculum and the remaining time engaged in recreation or other enjoyable activities during which Coaches model problem-solving and relationship skills. Coaches are supervised by the MST-EA clinical supervisor, and the transition skill corresponds with the goals set by the client and MST-EA therapist. Service duration was extended from the 3-5 months of standard MST to 4-12 months with MST-EA therapists, with support from Coaches lasting for up to an additional $2-4$ months, as needed.

As with standard MST, an intensive training and quality assurance system was used, ${ }^{76}$ which includes an off-site MST-EA expert (second and third authors) who conducts weekly telephone consultation and quarterly booster trainings with the team. MST-EA therapists were trained in standard MST plus the adaptations. Clinical supervisors trained the Coaches (4 hours) and provided weekly supervision.

The purpose of the current study was to investigate the feasibility of MST-EA and the research methods for investigating MST-EA efficacy. The primary goal of MST-EA is to reduce recidivism and symptoms of SMHC, and the secondary goals are reducing substance use (when present) and strengthening residential stability, engagement in age-appropriate activities (i.e., school and work), and social support.

\section{Method}

Participants

Recruitment-Recruitment for an open trial of MST-EA occurred in two research phases (described below). Recruitment for the first phase (Phase-1) occurred from 10/1/09 to $11 / 30 / 10$, and for the second phase (Phase-2) from $3 / 1 / 11$ to $1 / 31 / 13$. Eligibility criteria included: ages 17-20 at intake, recent arrest or release from incarceration (defined as within the past 18 months), presence of an Axis I mental health diagnosis (i.e., mood, anxiety, psychotic, and/or eating disorder), able to reside in a stable community setting (i.e., not currently homeless, not currently inpatient; can include individual ready for discharge to the 
community). Exclusion criteria included: actively psychotic, suicidal, or homicidal, and, because of the cognitive nature of the treatments, the presence of a pervasive developmental disorder or intellectual disability.

Participants were recruited from individuals receiving case management through child welfare or mental health services or receiving juvenile or adult justice system supervision services (e.g., probation) in an urban/suburban region of a Northeastern state. Program and research staff explained MST-EA and the research study to staff at child welfare and mental health area offices, corrections and juvenile facilities, and community mental health centers. The nature of the MST-EA intervention, research activities and research participation, and inclusion/exclusion criteria were described. Case managers, probation and parole officers, and service providers such as therapists (collectively, the referral sources) were asked to identify individuals on their caseloads that would be appropriate, and were provided information to help them identify the likely presence of a mental health condition since many individuals on their caseloads (other than for mental health case managers or mental health service providers) would not have mental health conditions. To refer an individual for the study, referral sources contacted research staff to verify likelihood of the emerging adult's eligibility (while maintaining client confidentiality) and availability of an opening in the intervention before contacting the emerging adult about study participation. Once likely eligibility was confirmed, referral sources contacted potential participants, briefly described the intervention, research, and the voluntary nature of participating, and asked for permission to provide contact information to researchers who would tell them the details of participation and the intervention. For 17 year olds, referral sources were required to obtain legal guardian permission before describing the research and intervention to the potential participant, and for providing researchers any contact information. Researchers then contacted the potential participant for screening and consenting.

Screening procedures included a formal assessment for the presence of a mental health condition, as well as confirmation of remaining eligibility criteria. Individuals who had previously met criteria for the state's public adult mental health services were considered to have met the criteria for having a mental health condition (one individual met this criteria). Screening by research staff for a mental health condition was achieved using the K-6 $6^{92}$ initially (first four referrals), but was deemed inadequate after being in conflict with multiple other sources' findings (e.g., recent in-depth psychiatric interviews and evaluations). For all subsequent screens, the Electronic Mini International Neuropsychiatric Interview (eM.I.N.I. $;^{93}$ ) was used. To minimize the time required by screening, individuals were deemed to have met the mental health criteria once they met the criteria for any qualifying diagnosis (i.e., the first diagnosis for which they met criteria, without completing items for any additional diagnoses). For those who screened in, informed consent for study participation was conducted by a research assistant. Research assistants emphasized the voluntary and confidential nature of participation, and that the study had obtained an NIH certificate of confidentiality to provide further protections for this justice-involved population. All procedures were reviewed and approved by the institutional review boards of the first author's institution and the state agency funding the clinical services, as well as a review board for the state agency that provides adult probation. 
Of the 69 individuals that referral sources discussed with research staff for initial review of eligibility, 8 did not meet preliminary eligibility (referral source's misunderstanding of age requirement, length of time since justice involvement, catchment area for the team, meaning of "stable community residence", or characteristics of mental illness). Of the remaining 61 individuals, all provided permission to the referral source for researchers to make contact and provided consent to undergo a formal eligibility screen. Eligibility screening indicated that 41 of the 61 cases $(67.6 \%)$ met the study inclusion criteria, and all consented to participate in the research. The current paper summarizes the feasibility and outcome data from the 16 participants from Phase- 1 and 25 from Phase- 2.

Study Phases-Study phases are a product of the investigators enhancing the research protocol to test feasibility of the changes prior to proposing a randomized controlled trial, as well as testing the feasibility of increasing the vocational emphasis within the model in response to early focus group data from MST-EA therapists. In Phase-1, participants were recruited into the study and all were provided with MST-EA. Data were collected at baseline (within 1 week before starting the intervention), and monthly for 12 months, with some additional measures obtained at baseline, 6 , and 12 months.

As part of the feasibility work for MST-EA, we were interested in examining the relative strength of providing clients with different types of vocational support. Thus, for Phase-2, participants were recruited into the study and provided MST-EA, but were randomized into one of two "vocational conditions." In one condition, the MST-EA Coaches (see subsequent explanation of MST-EA Coaches in the Clinical Procedures section) provided participants with extended vocational support. In the other condition, participants were referred to state vocational rehabilitation services for vocational support, and the MST-EA Coaches focused solely on standard independent living issues. Data during Phase-2 were collected at baseline (within one week before starting the intervention), bimonthly during the intervention, and at one and four months post intervention. Based on feedback from participants in Phase-1, the amount of data collected, along with frequency and length of interviews, was shortened for Phase-2.

Research Attrition-Of the 41 individuals in the study, all completed baseline interviews, and 37 completed a post-intervention interview. One individual could not be located, one individual declined to be interviewed post intervention, and two individuals (from Phase-1) completed the final interview but were still receiving services with the MST-EA Coach, so no "post-intervention" assessments were available. Analyses of outcomes are based on the 37 individuals for whom there are pre- and post-intervention data. Participants completed $91 \%$ of all scheduled interviews. Data on intervention attrition, satisfaction, and recidivism, which are not based on post-intervention interviews, are presented for the full sample $(\mathrm{N}=41)$.

\section{Clinical Procedures}

MST-EA was the clinical intervention provided to all participants. As is typical practice in the state in which MST-EA was developed and for many standard MST teams, the state agency charged with treatment of justice-involved adolescents and emerging adults 
contracted with a private non-profit provider to offer the MST-EA intervention. This community-based contractor delivered MST-EA, with therapists, the supervisor, and Coaches as employees of the contractor and with training and quality assurance provided by the MST-EA developers (second and third authors). In Phase-1, Coaches had a modest curriculum addressing employment. For Phase-2, Coaches were randomly assigned to one of the vocational conditions (i.e., Standard Coach conducting only the standard independent living curriculum, with no curriculum on employment or career exploration [vocational rehabilitation providing all vocational support] or Vocational Enhanced Coach conducting both standard and vocational curricula). For the Vocational Enhanced Coaches, the vocational curriculum was greatly enhanced from the modest one in Phase 1, and included 39 sessions covering five domains of employment (e.g. career exploration, job interviewing, keeping a job). Each Coach was trained only in the curriculum available for his/her assigned condition. In total, 3 individuals served as clinical supervisors, 6 as therapists, and 12 as coaches in the course of serving the 41 study participants.

\section{Data Collection Procedures}

Data for this study were collected from (1) participants, (2) therapist logs and clinical supervisor reports of intervention exposure, and (3) official arrest records. Participants completed a baseline interview. As described above, participants completed either monthly or bimonthly interviews, with Phase-1 participants completing a final interview at 12 months (referred to herein as a post-intervention interview), and Phase-2 participants completing a post-intervention interview at one and four months following the end of MST-EA service. For these analyses, the interview furthest post intervention was used (i.e., four months or one month if the four-month assessment was not completed). The mean number of weeks post intervention of the final interview across phases was $13.4(\mathrm{SD}=7.5)$. The two-hour baseline interviews assessed demographic and significant history factors, mental health and substance use symptoms, school and work functioning, residential quality, and quality of social supports. Post-intervention interviews assessed the same factors sans historic and demographic factors. Interviews were conducted face-to-face in participants' homes or another convenient place of their choosing, by trained research interviewers. Responses were entered into a RedCap ${ }^{\mathrm{TM}}$ web-based database, thus responses were automatically checked and stored. For sensitive items, such as substance use or peer delinquency, researchers had participants read and select responses on their own, with the researcher present to clarify items if needed, to increase participant willingness to report socially undesirable behavior. Researchers obtained therapist logs and clinical supervisor reports weekly, and entered the data into a database. Arrest records were obtained from the state's criminal and juvenile justice record systems for arrests that occurred up to six months prior to baseline and for six months post intervention.

In both phases, participants were given a $\$ 10$ gift card for completing screening procedures. In Phase-1, participants were given a $\$ 50$ gift card for completing the baseline and final interview, and in Phase- 2 they were given a $\$ 40$ and $\$ 30$ gift card for the baseline and final interview, respectively. Compensation was based on an estimate of the time to complete each assessment, at a rate of $\$ 20 / \mathrm{hr}$. compensation, the standard at the first author's institution. 


\section{Demographic Measures}

A variety of demographic and significant history variables were measured via a modified Structured Adolescent Interview, ${ }^{94}$ used in previous MST studies to assess demography and significant history. Modifications reflected the adult status of participants. Baseline functional status was also assessed using the mental health scale of the Medical Outcomes Health Survey Short Form 36 (SF-36), validated extensively with community and clinical samples, ${ }^{95}$ including those with mental illness. ${ }^{96,97}$

\section{Implementation Measures}

Attrition and Dose-The amount of therapist face-to-face and telephone time was recorded using therapist activity logs. Clinical supervisors reported Coach activity weekly. Therapists recorded the reason for client discharge, which was reviewed by the on-site MST-EA supervisor and the off-site clinical consultant to ensure accuracy (see Definitions in Table 1).

Satisfaction-Three items were used from the Client Satisfaction Questionnaire short form $^{98}$ to assess satisfaction with MST-EA services: Overall, how satisfied were you with this service? If you had the same problem again, would you return to this service? If you had a friend with a similar problem to yours, would you recommend this service to him or her? These three items account for $>85 \%$ of the variance in satisfaction scores using the CSQ-SF, and are considered a global measure of satisfaction. ${ }^{99}$

Fidelity-Within MST programs, treatment adherence is measured through a monthly 28item adherence questionnaire (Therapist Adherence Measure-Revised; TAM-R; ${ }^{100}$ ).

Nineteen TAM-R items are based on the nine MST treatment principles and whether treatment sessions focused on important aspects of the youths' school, peer, and neighborhood/social support systems, consistent with the MST model. These TAM-R items were examined for adherence to modifications in the MST-EA approach, resulting in the TAM-EA.

Initial item wording was reviewed by two youth with lived experience, and alpha tested with one study participant. The resulting TAM-EA was beta tested with 9 participants in 18 administrations. Initial feedback resulted in rewording of some items, splitting complex items into two separate items, and reorganizing items for domain clarity. This version was used with the 20 participants completing interviews between 4/28/10 and 11/28/11, in 101 administrations regarding 3 therapists (therapists B, C, \& D). Based on analysis of item intercorrelations and a review of the concreteness of the participant-rated therapist behaviors, the TAM-EA was revised slightly to form the final version, which was administered to the 18 participants completing interviews between 11/29/11 and the end of the study, in 41 administrations (some participants completed more than one version of the TAM-EA) regarding 3 therapists (therapists C, D \& E). Two therapists (A \& F) had insufficient data to include in the analysis. One took another job shortly after beta testing was completed, and the other was hired shortly before the end of the study. In addition to the TAM-EA, a separate measure was developed to examine Coach Adherence (CAM-EA). Because there were two different Coach approaches utilized in Phase-2, the second version 
of the CAM-EA (utilized with the 25 Phase-2 participants) included additional items to ensure differentiation of the two Coaching conditions.

\section{Ultimate Outcomes Measures}

Mental Health-Mental health symptoms were assessed using the Brief Symptom Inventory (BSI: ${ }^{101}$ ), a 53-item self-report inventory designed to provide multidimensional mental health symptom measurement in less than 10 minutes. Internal consistency is acceptable (Cronbach's alphas=.71-.83), and test-retest reliability is good (.68-.91).

Recidivism-Recidivism was assessed using state justice system records.

\section{Instrumental Outcomes Measures}

Relationships-Antisocial peer relationships were measured using the Peer Delinquency section from the Pathways to Desistance Study. ${ }^{102}$ These 19 items measure the number of friends who engage in antisocial activity (e.g., During the past month how many of your friends have hit or threatened to hit someone?). Items were derived from several questionnaires about delinquent peer relationships. ${ }^{55,103,104}$ A one-factor CFA model was fit to the Pathways baseline data for this subscale. Quality of social support was assessed with the Norbeck Social Support Questionnaire (NSSQ:105,106), which asks youth to list all individuals that provide them social support and then asks them to rate each relationship on 10 items that tap the affective nature of the relationship, its degree of affirmation, and the aid provided. Items are rated on a 5-point Likert scale from 0 (not at all) to 4 (A great deal). Test-retest reliability is acceptable with both non-clinical $(r>.85)$ and clinical (Cronbach's alphas $>.90 ;{ }^{107}$ ) samples. There is adequate evidence of concurrent and predictive validity in non-clinical populations, ${ }^{108}$ and concurrent validity in clinical populations. ${ }^{107}$

Employment and Schooling-Participants answered questions about paid employment and schooling during the past 30 days. Employment items assessed (a) days worked, hours per day and (b) nature of job (e.g., "under the table jobs" such as landscaping and child care vs. jobs that are "on the books"). Participants were also asked if they attended school or training (e.g., job training programs).

Residential Status-Participants answered questions about where they resided in the past 30 days. Participants selected from a list of 14 residential settings (e.g., home with family, residential treatment setting, own home) used to describe residential settings in previous MST studies. Residences were categorized into four categories: On own (living alone, with spouse/partner, or with friends), With Family (living with immediate or extended family), Institutional (any out-of-home setting), or Homeless.

Substance Use-The Global Appraisal of Individual Needs (GAIN; ${ }^{109}$ ) is a standardized bio-psychosocial interview that includes more than 100 scales and subscales. The 16-item Substance Problem Scale was used to assess past-month symptoms related to any alcohol or drug use disorders including abuse or dependence. The GAIN has strong psychometric properties and validation data. ${ }^{110-113}$ 


\section{Analysis Plan}

Descriptive statistics were used to explore participant characteristics, as well as different aspects of the MST-EA intervention: participant attrition, duration and amount of intervention received, satisfaction with the intervention, and levels of intervention fidelity for therapists and Coaches. Given the relatively small number of participants, nonparametric related-samples tests were used to compare outcomes between baseline and postintervention assessments (related samples Wilcoxon Signed Rank Tests for continuous data, Related Samples McNemar Test for binary data, Related Samples Homogeneity Test for ordinal data).

\section{Results}

\section{Participant Characteristics}

Characteristics of the study sample can be found in Table 2. Almost half were age 17 at enrollment, the majority were male, and a substantial portion were Black. Approximately $21 \%$ of the sample was Hispanic. The majority of participants had a history of psychiatric hospitalization and juvenile detention. Participants primarily lived on their own or with family in the year prior to recruitment. Participants were most commonly referred by criminal justice sources, followed by child welfare and juvenile justice sources (i.e., the state where this study was conducted maintained some young adult offenders in the juvenile system).

\section{Intervention Feasibility}

Attrition-Reasons for discharge are described in Table 1. Of the 41 participants who enrolled in the study, $21(51.2 \%)$ fully finished the intervention, with 36.5 (range = 14.764.8). median weeks of intervention. For 6 participants (14.6\%), intervention ended by mutual agreement, though not all goals had been met or were sustainable (median duration $=$ 34.8 weeks, range $=21.2-47.8)$. Intervention ended with 7 participants $(17.1 \%)$ due to indirect ending by client (median duration $=14.4$ weeks, range $=6.4-23.4$ ). Only one participant explicitly ended prior to achieving goals (treatment duration $=10.3$ weeks). Entry into restrictive treatment settings resulted in ending for 5 participants (12.2\%; median duration $=19.3$ weeks, range $=8.7-49.6$ ). One individual moved away prior to completing (duration $=24.0$ weeks).

Intervention Amount and Satisfaction-The median number of weeks receiving MST-EA was 28.0 and ranged widely (6.4-64.8). The median number of weeks of treatment with MST-EA therapists (i.e., not including time with Coaches) was 25.0 (range $=6.4$ 48.6). For those who agreed to work with a Coach $(n=33)$, median weeks of receiving Coach services was 28.3 (range $=6.4-64.8$ ). The median number of face-to-face meetings participants had with therapists was 29.5 (range $=5-76$ ). The median duration of face-to-face therapist meetings was 60 minutes (range $=5-470$ ). Phone contact frequency and duration between therapist and client have not yet been analyzed. The median (across months assessed) score on the client satisfaction index, assessed each month that services were received $(n=41)$, was 10.1 (highest possible score $=12$; range $=5.7-12.0$ ). 
Intervention Fidelity-Fidelity scores with the first TAM-EA version after beta testing $(\mathrm{n}=3$ therapists [therapists $\mathrm{B}, \mathrm{C}, \& \mathrm{E}$ ], based on 20 participant ratings in, 101 administrations) indicated overall high fidelity to the MST-EA model. Possible total scores range from 47 (all items rated "Never") to 188 (all items rated "Always"), with a median of 149.2 (Range=65.2-188.0), demonstrating high treatment fidelity. Differences in scores between therapists approached significance (Kruskal-Wallis Test $=5.3, d f=2, p=.07$ ). Correlation between the month of participant treatment and therapist fidelity score was not significant (Pearson $r=.06, p>.10$ ). The final TAM-EA version, containing 27 items (possible scores $=27-108$ ), assessed three therapists ( $\mathrm{n}=3$ [therapists $\mathrm{C}, \mathrm{D}, \& \mathrm{E}$ ]), as administered to 18 participants in 45 administrations. The median total score was 95.0 (Range $=44-108$ ), indicating implementation with strong fidelity, good variability, and no ceiling of floor effects. There were no significant differences in the scores between therapists (Kruskal-Wallis Test $=2.0, d f=2, p>.10$ ), and no significant correlation between month of participant treatment and therapist fidelity score (Pearson $r=.15, p>.10$ ).

The original CAM-EA included 4 items assessing Coach adherence (possible scores 4-16, $\mathrm{n}=7$ [Coaches A-G], assessed by 10 participants, in 52 administrations). Use of Coaches were encouraged, but not required, and not all participants opted to utilize a Coach. The median score was 12.0 (Range $=4-16$ ), indicating good adherence and variability in scores. There was no correlation between month since participant intervention start and CAM-EA score (Pearson $r=.05, p>.10$ ). Additional items were added in Phase-2 to reflect differences between Standard Coaching ( $\mathrm{n}=3$; Coaches H, I, \&L) and the Vocational Enhanced Coaching ( $\mathrm{n}=3$; Coaches G, J, \&K), and were assessed by 13 participants in 50 administrations. Total possible scores ranged from 7-28 (median $=23.5$, Range $=10-28$ ). There was a significant difference between the two types of Coaches, indicating differentiation albeit not directly related to vocational skills training. Vocational Enhanced Coaches had higher total scores (median $=25.0$, range $=10-28)$ than Standard Coaches $($ median $=22.0$, range $=12-27$; Independent Samples median test $=8.1, d f=1, p<.005)$. This difference reflected significantly lower scores among Standard Coaches for teaching needed skills $\left(\chi^{2}=13.2, d f=3, p<.005\right)$, having fun with the Coach $\left(\chi^{2}=8.2, d f=3, p<\right.$. $05)$, and Coaches knowing client's strengths $\left(\chi^{2}=8.8, d f=3, p<.05\right)$. Because Coaches had different skills they could teach, additional items asked about 20 specific skills that could be addressed. As expected, participants with Vocational Enhanced Coaches reported their coaches addressed skills related to working more often than participants with Standard Coaches. Indeed, the Vocational Enhanced Coaches were more likely than the Standard Coaches to determine the kinds of work that interested participants $\left(35.7 \%\right.$ vs. $4.5 \%, \chi^{2}=$ $7.0, d f=1, p<.01)$ and to assist participants in obtaining a job $\left(60.7 \%\right.$ vs. $18.2 \%, \chi^{2}=9.1$, $d f=1, p<.005)$. The only other skill that was significantly different between conditions in favor of Standard Coaches was working on getting or using transportation (21.4\% vs. $\left.54.5 \%, \chi^{2}=5.9, d f=1, p<.05\right)$.

\section{Intervention Outcomes}

Change in Ultimate Outcomes-As can be seen in Table 3, there was a significant reduction in mental health symptoms, with the median number falling substantially from 20 symptoms to between 5 and 6 . The number of criminal and juvenile charges in the 6 months 
post intervention was less than those in the 6 months prior to baseline. Although the median for both timeframes was 0 , the range reported in Table 3 highlights the reduction picked up by the nonparametric statistic. While the rate of arrests dropped by 17 points in the 6 months post intervention compared to the 6 months prior to treatment, this reduction did not reach statistical significance. Of note, this population has high rates of suicidality and homicidality, but no deaths (of MST-EA clients or as a result of MST-EA clients) occurred during the study.

All pre to post comparisons were conducted with nonparametric tests due to the small sample size, but results of parametric tests (not shown) yielded the same findings of significance.

Change in Instrumental Outcomes-As can be seen in Table 3, participants had a significant reduction in exposure to peer delinquency. There were no other significant changes in instrumental outcomes, though change was in the anticipated direction for social support, working, living in out-of-home settings, and substance use. For example, the percent of participants working doubled and the percent of participants in out-of-home placements was cut by more than half. No participants were homeless at baseline (criteria for eligibility), and only one participant reported being homeless post intervention.

\section{Discussion}

This feasibility study of an adaptation of MST for use with emerging adults with SMHC and recent justice system involvement indicates positive findings that justify subsequent testing of MST-EA in a large clinical trial. Importantly, the changes in ultimate outcomes for mental health symptoms and criminality were positive and, with one exception, statistically significant, even with a small sample size. The changes in instrumental outcomes, which focus on positive functioning, also were modestly in a positive direction and reductions in exposure to delinquent peers reached statistical significance.

There are few interventions with which to compare the 51\% MST-EA intervention completion rates. However, the array of retention rates in individual, outpatient cognitive behavioral therapies ranges widely including $55 \%$ for eating disorders, ${ }^{114} 61 \%$ for medication adherence in adults with HIV and serious alcohol use problems, ${ }^{115}$ and $83 \%$ for obsessive compulsive disorder in adults. ${ }^{116}$ Given that young adults have the highest outpatient mental health treatment dropout rates among adults, ${ }^{117,118}$ and substance use contributes to treatment dropout (e.g. ${ }^{119}$ ), the high MST-EA recruitment rate overall and the long lengths of stay observed, even for cases that did not complete treatment successfully, are positive, as are the client satisfaction results. Notably, though clients could continue with a Coach for up to four months after ending with therapists, Coaches and clients generally ended their work about a month after ending with the therapists. This may suggest that extensive work with Coaches to sustain the changes made during treatment is either not needed or not desired by clients. It also could be that the longer length of time working with the MST-EA therapist, compared to standard MST, provides adequate time to solidify sustainability for the client. The Coach component of the MST-EA model is probably the most innovative adaptation element, so continued evaluation and possibly improvement is 
necessary. The preliminary and final fidelity measures for both the Coaches and the therapists indicated implementation with good fidelity. Thus, although this population is much more complex to treat and has greater safety needs, the MST-EA model provided a safe and potentially efficacious intervention. The model, although more complex than standard MST, can feasibly and safely be implemented in a community-based agency by "real world" therapists.

Vocational success is a key outcome during the years when youth transition to adulthood. Employment and mental health status are correlated during young adulthood ${ }^{67}$, and working is associated with reduced or delayed recidivism (e.g. ${ }^{17,54}$ ) But, vocational outcomes for emerging adults with mental health conditions are poorer than (a) emerging adults without mental health conditions (e.g.. $\left.{ }^{6}\right)$ and (b) more mature adults with mental health conditions. ${ }^{120}$ While there were no significant changes in the work outcomes, the lowest rate of increase was for those clients who had a standard MST-EA Coach and had to obtain vocational assistance from the state vocational rehabilitation agency. The MST-EA team members expressed consistent frustration with the slowness of access to state vocational rehabilitation services, lack of outreach by the rehabilitation agency, and few actual supports provided. Given this experience, the relatively less robust increase in employment in this group, the feasibility of MST-EA Coaches providing vocational skills, and the positive reports on the CAM-EA by clients receiving this enhancement, future MSTEA versions will implement the Vocational Enhanced Coach as standard practice in the MST-EA model. As is the case with standard MST, connecting clients with other services such as vocational rehabilitation services will be done as needed during treatment or discharge (or continued during treatment if clients are already engaged and satisfied with such services).

In addition to the clinical findings in this feasibility trial, the feasibility findings for the research methods were also encouraging. Recruitment rates into the research were high, and research retention rates were also very strong, as were interview completion rates. Selected measures showed good variability with results generally detecting change. The final fidelity measure captured adequate variability, and participants expressed no confusion about final items.

Given that the essential purpose of feasibility trials is to refine the clinical approach and research methods, study limitations include the absence of a control group, and the absence of examining the feasibility of randomization to a control condition. The absence of a control group limits understanding the relative strengths or weaknesses of the outcomes; however, that would be the main goal of a larger randomized controlled trial. The absence of employing randomization procedures limits the ability to specifically predict recruitment and retention issues that may arise as a result of either randomization or being assigned to a control condition.

\section{Implications for Behavioral Health}

There are currently no interventions with strong evidence of efficacy for recidivism reduction and delivery of good mental health care for emerging adults with SMHC and 
justice system involvement. The current study demonstrates that an adaptation of MST that addresses the likely causes of recidivism in emerging adults and delivers good quality mental health treatment is feasible. Further, results demonstrate that emerging adults with SMHC and justice involvement who received MST-EA had positive changes from baseline to post intervention in the ultimate outcomes of recidivism reduction and mental health symptoms. These findings suggest that research on MST-EA should progress to large clinical trials to determine its efficacy.

\section{Acknowledgments}

This work was supported by grants from the National Institute of Mental Health (R34MH081374) and the National Institute on Disability and Rehabilitation Research (H133B090018) to Dr. Davis. Content is solely the responsibility of the authors and does not necessarily represent the official views of these agencies. The authors gratefully acknowledge the support of the Connecticut Department of Children and Families and North American Family Institute, as well as advice from Drs. Mary Evans, Scott Henggeler, Charles Lidz, and Edward Mulvey. We also thank the young adults and their social network members who made this research possible.

\section{References}

1. Blumstein, A.; Cohen, J.; Roth, JA., et al. Criminal Careers and Career Criminals. Vol. 2. Washington, DC: National Academy Press; 1986.

2. Ageton, SS.; Huizinga, D.; Knowles, BA., et al., editors. The Prevalence and Incidence of Delinquent Behavior 1976-1980: National Estimates of Delinquent Behavior by Sex, Race, Social Class and Other Selected Variables. Boulder, CO: Behavioral Research Institute; 1983.

3. Wolfgang, ME.; Thornberry, TP.; Figlio, RM. From Boy to Man, From Delinquency to Crime. Chicago, IL: University of Chicago Press; 1987.

4. Davis M, Fisher WH, Gershenson B, et al. Justice system involvement into young adulthood: comparison of adolescent girls in the public mental health system and in the general population. American Journal of Public Health. 2009; 99(2):234-236. [PubMed: 19059845]

5. Arnett JJ. Emerging adulthood: A theory of development from the late teens through the twenties. American Psychologist. 2000; 55(5):469-480. [PubMed: 10842426]

6. Vander Stoep A, Beresford SA, Weiss NS, et al. Community-based study of the transition to adulthood for adolescents with psychiatric disorder. American Journal of Epidemiology. 2000; 152(4):352-362. [PubMed: 10968380]

7. Vander Stoep A, Evens CC, Taub J. Risk of juvenile justice system referral among children in a public mental health system. The Journal of Mental Health Administration. 1997; 24(4):428-442.

8. Yampolskaya S, Chuang E. Effects of mental health disorders on the risk of juvenile justice system involvement and recidivism among children placed in out-of-home care. American Journal of Orthopsychiatry. 2012; 82(4):585-593. [PubMed: 23039356]

9. Davis M, Fisher WH, Gershenson B, et al. Justice system involvement into young adulthood: Comparison of adolescent girls in the public mental health system and in the general population. American Journal of Public Health. 2009; 99(2):234-236. [PubMed: 19059845]

10. Hoeve M, Mcreynolds LS, Wasserman GA. The influence of adolescent psychiatric disorder on young adult recidivism. Criminal Justice Behavior. 2013; 40(12):1368-1382.

11. Fisher WH, Silver E, Wolff N. Beyond criminalization: Toward a criminologically informed framework for mental health policy and services research. Administration and Policy in Mental Health and Mental Health Services Research. 2006; 33(5):544-557. [PubMed: 16791518]

12. Wagner MM. Outcomes for youths with serious emotional disturbance in secondary school and early adulthood. The Future of Children. 1995:90-112. [PubMed: 8528691]

13. Davis M, Banks S, Fisher W, et al. Longitudinal patterns of offending during the transition to adulthood in youth from the mental health system. Journal of Behavioral Health Services and Research. 2004; 31:351-366. [PubMed: 15602138] 
14. Davis M, Banks S, Fisher W, et al. Arrests of adolescent clients of a public mental health system during adolescence and young adulthood. Psychiatric Services. 2007; 58(11):1454-1460. [PubMed: 17978256]

15. Haberman M, Quinn LM. The high school re-entry myth: A follow-up study of juveniles released from two correctional high schools in Wisconsin. Journal of Correctional Education. 1986; 37(3): $114-117$.

16. Kaufman, P.; Alt, MN.; Chapman, CD. Dropout Rates in the United States: 2000. Washington, DC: National Center for Education Statistics, US Department of Education; 2001.

17. Sampson RJ, Laub JH. Crime and deviance over the life course: The salience of adult social bonds. American Sociological Review. 1990; 55(5):609-627.

18. Fagan, J.; Freeman, RB. Crime and work. In: Tonry, M., editor. Crime and Justice: A Review of Research. Chicago, IL: University of Chicago Press; 1999. p. 225-290.

19. Freeman, RB. Crime and the economic status of disadvantaged young men. In: Peterson, G.; Vroman, W., editors. Urban Labor Markets and Job Opportunities. Washington, DC: Urban Institute Press; 1992. p. 112-152.

20. Grogger J. The effect of arrests on the employment and earnings of young men. The Quarterly Journal of Economics. 1995; 110(1):51-71.

21. Moffitt, TE.; Caspi, A.; Rutter, M., et al., editors. Sex Differences in Antisocial Behavior. Cambridge, UK: Cambridge University Press; 2001.

22. Laub JH, Nagin DS, Sampson RJ. Trajectories of change in criminal offending: Good marriages and the desistance process. American Sociological Review. 1998; 63(2):225-238.

23. Henggeler, SW.; Schoenwald, SK.; Borduin, CM., et al. Multisystemic Treatment of Antisocial Behavior in Children and Adolescents. New York, NY: Guilford Press; 1998.

24. Chamberlain P, Leve LD, DeGarmo DS. Multidimensional treatment foster care for girls in the juvenile justice system: 2-Year follow-up of a randomized clinical trial. Journal of Consulting and Clinical Psychology. 2007; 75(1):187. [PubMed: 17295579]

25. U.S. Public Health Service. Youth violence: A report of the Surgeon General. Rockville, MD: Office of the Surgeon General; 2001.

26. Perry A, Coulton S, Glanville J, et al. Interventions for drug-using offenders in the courts, secure establishments and the community. Cochrane Database of Systematic Reviews. 2006; 3:1-65.

27. Wilson DB, Gallagher CA, MacKenzie DL. A meta-analysis of corrections-based education, vocation, and work programs for adult offenders. Journal of Research Crime and Delinquency. 2000; 37(4):347-368.

28. Seiter RP, Kadela KR. Prisoner reentry: What works, what does not, and what is promising. Crime \& Delinquency. 2003; 49(3):360-388.

29. Gaes GG, Flanagan TJ, Motiuk LL, et al. Adult correctional treatment. Crime and Justice. 1999; 26:361-426.

30. Lipsey MW, Chapman GL, Landenberger NA. Cognitive-behavioral programs for offenders. The Annals of American Academy of Political and Social Science. 2001; 578(1):144-157.

31. Pearson FS, Lipton DS, Cleland CM, et al. The effects of behavioral/cognitive-behavioral programs on recidivism. Crime \& Delinquency. 2002; 48(3):476-496.

32. Uggen C. Work as a turning point in the life course of criminals: A duration model of age, employment, and recidivism. American Sociological Review. 2000; 65(4):529-546.

33. Braga AA, Piehl AM, Hureau D. Controlling violent offenders released to the community: An evaluation of the Boston Reentry Initiative. Journal of Research in Crime and Delinquency. 2009; 46(4):411-436.

34. Josi DA, Sechrest DK. A pragmatic approach to parole aftercare: Evaluation of a community reintegration program for high-risk youthful offenders. Justice Quarterly. 1999; 16(1):51-80.

35. Barrenger SL, Draine J. "You don't get no help": The role of community context in effectiveness of evidence-based treatments for people with mental illness leaving prison for high risk environments. American Journal of Psychiatric Rehabilitation. 2013; 16(2):154-178. 
36. Draine, J. Where is the 'illness' in the criminalization of mental illness?. In: Fisher, W., editor. Community-Based Interventions for Criminal Offenders with Severe Mental Illness. Vol. 12. Oxford: Emerald Group Publishing Limited; 2003. p. 9-21.

37. Schubert CA, Mulvey EP, Glasheen C. Influence of mental health and substance use problems and criminogenic risk on outcomes in serious juvenile offenders. Journal of the American Academy of Child \& Adolescent Psychiatry. 2011; 50(9):925-937. [PubMed: 21871374]

38. Steadman HJ, Morris SM, Dennis DL. The diversion of mentally ill persons from jails to community-based services: a profile of programs. American Journal of Public Health. 1995; 85(12):1630-1635. [PubMed: 7503336]

39. Hartford K, Carey R, Mendoca J. Pretrial court diversion of people with mental illness. Journal of Behavioral Health Services and Research. 2007; 34(2):198-205. [PubMed: 17353994]

40. Skeem JL, Emke-Francis P, Louden JE. Probation, mental health, and mandated treatment: A national survey. Criminal Justice Behavior. 2006; 33(2):158-184.

41. Evens CC, Stoep AV. Risk factors for juvenile justice system referral among children in a public mental health system. Journal of Behavioral Health Services and Research. 1997; 24(4):443-455.

42. Bryant, E.; Rivard, J.; Cowan, T., et al. Frequency and correlates of juvenile justice system involvement among children and adolescents with severe emotional disturbance. In: Liberton, C.; Friedman, RM., editors. The 7th Annual Conference Proceedings: A System of Care for Children's Mental Health: Expanding the Research Base. Tampa, FL: Research and Training Center for Children's Mental Health; 1995. p. 295-302.

43. Elander J, Simonoff E, Pickles A, et al. A longitudinal study of adolescent and adult conviction rates among children referred to psychiatric services for behavioural or emotional problems. Criminal Behaviour and Mental Health. 2000; 10(1):40-59.

44. Schafer JL, Olsen MK. Multiple imputation for multivariate missing-data problems: A data analyst's perspective. Multivariate Behavioral Research. 1998; 33(4):545-571.

45. Robins, LN., editor. Deviant Children Grown Up: A Sociological and Psychiatric Study of Sociopathic Personality. Baltimore, MD: Williams and Wilkins; 1966.

46. Bonta J, Law M, Hanson K. The prediction of criminal and violent recidivism among mentally disordered offenders: a meta-analysis. Psychological Bulletin. 1998; 123(2):123-142. [PubMed: 9522681]

47. Swanson JW, Swartz MS, Essock SM, et al. The social-environmental context of violent behavior in persons treated for severe mental illness. American Journal of Public Health. 2002; 92(9):15231531. [PubMed: 12197987]

48. Benda BB. Undomiciled: A study of drifters, other homeless persons, their problems, and service utilization. Psychosocial Rehabilitation Journal. 1991; 14:40-67.

49. Swanson JM, Wigal SB, Wigal T, et al. A comparison of once-daily extended-release methylphenidate formulations in children with attention-deficit/hyperactivity disorder in the laboratory school (the Comacs Study). Pediatrics. 2004; 113(3):206-216.

50. Matsueda RL, Heimer K. Race, family structure, and delinquency: A test of differential association and social control theories. American Sociological Review. 1987; 52:826-840.

51. Loeber, R.; Stouthamer-Loeber, M. Family factors as correlates and predictors of juvenile conduct problems and delinquency. In: Tonry, M.; Morris, N., editors. Crime and Justice. 7. Vol. 7. Chicago: University of Chicago Press; 1986. p. 29-149.

52. Farrall, S. Social capital and offender reintegration: making probation desistance focused. In: Maruna, S.; Immarigeon, R., editors. After Crime and Punishment: Pathways to Offender Reintegration. Portland, OR: Willan Publishing; 2004. p. 57-82.

53. Laub JH, Sampson RJ. Strategies for bridging the quantitative and qualitative divide: Studying crime over the life course. Research in Human Development. 2004; 1(1):81-99.

54. Visher CA, Travis J. Transitions from prison to community: Understanding individual pathways. Annual Review of Sociology. 2003; 29:89-113.

55. Elliott, DS.; Menard, S. Delinquent friends and delinquent behavior: Temporal and developmental patterns. In: Hawkins, DJ., editor. Delinquency and Crime: Current Theories. New York, NY: Cambridge University Press; 1996. p. 28-67. 
56. Warr M, Stafford M. The influence of delinquent peers: What they think or what they do? Criminology. 1991; 29(4):851-866.

57. Alarid LF, Burton VS, Cullen FT. Gender and crime among felony offenders: Assessing the generality of social control and differential association theories. Journal of Research in Crime and Delinquency. 2000; 37(2):171-199.

58. Hochstetler A, Copes H, DeLisi M. Differential association in group and solo offending. Journal of Criminal Justice. 2002; 30(6):559-566.

59. Best D, Hernando R, Gossop M, et al. Getting by with a little help from your friends: The impact of peer networks on criminality in a cohort of treatment-seeking drug users. Addictive Behaviors. 2003; 28(3):597-603. [PubMed: 12628631]

60. Williamson GM, Silverman JG. Violence against female partners: Direct and interactive effects of family history, communal orientation, and peer-related variables. Journal of Social and Personal Relationships. 2001; 18(4):535-549.

61. Higgins GE, Makin DA. Self-control, deviant peers, and software piracy. Psychological Reports. 2004; 95(3):921-931. [PubMed: 15666930]

62. Sampson RJ, Laub JH. Life-course desisters? Trajectories Of crime among delinquent boys followed to age 70. Criminology. 2003; 41(3):555-592.

63. Pogarsky G, Piquero AR, Paternoster R. Modeling change in perceptions about sanction threats: The neglected linkage in deterrence theory. Journal of Quantitative Criminology. 2004; 20(4):343369.

64. Paternoster R. The deterrent effect of the perceived certainty and severity of punishment: A review of the evidence and issues. Justice Quarterly. 1987; 4(2):173-217.

65. Scheider MC. Deterrence and the base rate fallacy: An examination of perceived certainty. Justice Quarterly. 2001; 18(1):63-86.

66. Matsueda RL, Kreager DA, Huizinga D. Deterring delinquents: A rational choice model of theft and violence. American Sociological Review. 2006; 71(1):95-122.

67. Fergusson DM, Horwood LJ, Lynskey MT. The effects of unemployment on psychiatric illness during young adulthood. Psychological Medicine. 1997; 27(02):371-381. [PubMed: 9089830]

68. Huang B, White HR, Kosterman R, et al. Developmental associations between alcohol and interpersonal aggression during adolescence. Journal of Research in Crime and Delinquency. 2001; 38(1):64-83.

69. Krueger RF, Hicks BM, Patrick CJ, et al. Etiologic connections among substance dependence, antisocial behavior and personality: Modeling the externalizing spectrum. Journal of Abnormal Psychology. 2002; 111(3):411. [PubMed: 12150417]

70. Stroul, BA.; Friedman, RM., editors. A System of Care for Children and Youth with Severe Emotional Disturbances. Washington, DC: CASSP Technical Assistance Center, Georgetown University Child Development Center; 1994.

71. Burns BJ, Hoagwood K, Mrazek PJ. Effective treatment for mental disorders in children and adolescents. Clinical Child and Family Psychology Review. 1999; 2(4):199-254. [PubMed: 11225935]

72. Elliott, DS., editor. Blueprints for violence prevention. Boulder, CO: Blueprints Publications; 2001.

73. Farrington DP, Welsh BC. Delinquency prevention using family-based interventions. Children \& Society. 1999; 13(4):287-303.

74. Kazdin AE, Weisz JR. Identifying and developing empirically supported child and adolescent treatments. Journal of Consulting and Clinical Psychology. 1998; 66(1):19-36. [PubMed: 9489260]

75. Stanton MD, Shadish WR. Outcome, attrition, and family-couples treatment for drug abuse: A meta-analysis and review of the controlled, comparative studies. Psychology Bulletin. 1997; 122(2):170-191.

76. Damon W. What is positive youth development? The Annals of the American Academy of Political and Social Science. 2004; 591:13-24.

77. Larson RW. Towards a psychology of positive youth development. American Psychologist. 2000; 55:170-183. [PubMed: 11392861] 
78. Lerner, RM. The positive youth development perspective: theoretical and empirical bases of a strength-based approach to adolescent development. In: Snyder, CR.; Lopez, SJ., editors. Oxford Handbook of Positive Psychology. 2. Oxford, England: Oxford University Press; 2009. p. 149-163.

79. Mueller MK, Phelps E, Bowers EP, Agans JP, Brown Urban J, Lerner RM. Youth development program participation and intentional self-regulation skills: Contextual and individual bases of pathways to positive youth development. Journal of Adolescence. 2011; 34:1115-1125. [PubMed: 22118505]

80. Overton, WF. Life-span development: concepts and issues. In: Lerner, RM.; Overton, WF., editors. The Handbook of Life-Span Development. Cognition, Biology, and Methods. Vol. 1. Hoboken, NJ: Wiley; 2010. p. 1-29.

81. Henggeler, SW.; Schoenwald, SK.; Rowland, MD., et al., editors. Serious Emotional Disturbance in Children and Adolescents: Multisystemic Therapy. New York: Guilford Press; 2002. a Bronfenbrener, U. The Ecology of Human Development: Experiments by Design and Nature. Cambridge, MA: Harvard University Press; 1979.

82. Zajac, K.; Sheidow, A.; Davis, M. Transition age youth with mental health challenges in the juvenile justice system. Washington, DC: Technical Assistance Partnership for Child and Family Mental Health; 2013.

83. Pullmann MD, Heflinger CA, Mayberry LS. Patterns of Medicaid disenrollment for youth with mental health problems. Medical Care Research and Review. 2010; 67(6):657-675. [PubMed: 20555015]

84. Pottick KJ, Bilder S, Vander Stoep A, et al. US patterns of mental health service utilization for transition-age youth and young adults. Journal of Behavioral Health Services and Research. 2008; 35(4):373-389. [PubMed: 18026842]

85. Pottick KJ, Warner LA, Vander Stoep A, et al. Clinical characteristics and outpatient mental health service use of transition-age youth in the USA. Journal of Behavioral Health Services \& Research. 2013:1-14. [PubMed: 23334655]

86. Henggeler, S.; Schoenwald, S.; Rowland, M., et al., editors. Multisystemic Treatment of Children and Adolescents with Serious Emotional Disturbance. New York: Guilford; 2002.

87. Antonucci TC, Akiyama H, Lansford JE. Negative effects of close social relations. Family Relations. 1998; 47(4):379-384.

88. Miller, WR.; Rollnick, S. Motivational Interviewing: Preparing People to Change. 2. New York: Guilford Press; 2002.

89. Rhodes, JE., editor. Stand By Me: The Risks and Rewards of Mentoring Today's Youth. Cambridge, MA: Harvard University Press; 2004.

90. Karcher MJ, Kuperminc GP, Portwood SG, et al. Mentoring programs: A framework to inform program development, research, and evaluation. Journal of Community Psychology. 2006; 34(6): 709-725.

91. Hamilton, MA.; Hamilton, SF. Work and service-learning. In: Dubois, D.; Karcher, MJ., editors. Handbook of Youth Mentoring. Thousand Oaks, CA: Sage; 2005. p. 348-363.

92. Kessler RC, Barker PR, Colpe LJ, et al. Screening for serious mental illness in the general population. Archives of General Psychiatry. 2003; 60(2):184-189. [PubMed: 12578436]

93. Lecrubier Y, Sheehan D, Weiller E, et al. The Mini International Neuropsychiatric Interview (MINI). A short diagnostic structured interview: Reliability and validity according to the CIDI. European Psychiatry. 1997; 12(5):224-231.

94. Brown SA. Life events of adolescents in relation to personal and parental substance abuse. American Journal of Psychiatry. 1989; 146(4):484-489. [PubMed: 2929749]

95. Ware JE. SF-36 Health survey update. SPINE. 2000; 25(24):3130-3139. [PubMed: 11124729]

96. Russo J, Trujillo CA, Wingerson D, et al. The MOS 36-Item Short Form Health Survey: reliability, validity, and preliminary findings in schizophrenic outpatients. Medical Care. 1998; 36(5):752756. [PubMed: 9596066]

97. Sciolla A, Patterson TL, Wetherell JL, et al. Functioning and well-being of middle-aged and older patients with schizophrenia: measurement with the 36-item short-form (SF-36) health survey. American Journal of Geriatric Psychiatry. 2003; 11(6):629-637. [PubMed: 14609803] 
98. Attkisson CC, Zwick R. The client satisfaction questionnaire: Psychometric properties and correlations with service utilization and psychotherapy outcome. Evaluation and Program Planning. 1982; 5(3):233-237. [PubMed: 10259963]

99. Larsen DL, Attkisson CC, Hargreaves WA, et al. Assessment of client/patient satisfaction: Development of a general scale. Evaluation and Program Planning. 1979; 2(3):197-207. [PubMed: 10245370]

100. Henggeler SW, Halliday-Boykins CA, Cunningham PB, et al. Juvenile drug court: Enhancing outcomes by integrating evidence-based treatments. Journal of Consulting and Clinical Psychology. 2006; 74(1):42-54. [PubMed: 16551142]

101. Derogatis LR, Melisaratos N. The brief symptom inventory: An introductory report. Psychological Medicine. 1983; 13:595-605. [PubMed: 6622612]

102. Schubert CA, Mulvey EP, Steinberg L, et al. Operational lessons from the pathways to desistance project. Youth Violence and Juvenile Justice. 2004; 2(3):237-255. [PubMed: 20119515]

103. Thornberry TP, Lizotte AJ, Krohn MD, et al. Delinquent peers, beliefs, and delinquent behavior: A longitudinal test of interactional theory. Criminology. 1994; 32(1):47-83.

104. Elliott, D. National Youth Survey (United States): Wave I, 1976. ICPSR Version. Boulder, CO: University of Colorado; 1994.

105. Norbeck JS, Lindsey AM, Carrieri VL. The development of an instrument to measure social support. Nursing Research. 1981; 30(5):264-269. [PubMed: 7027185]

106. Norbeck JS, Lindsey AM, Carrieri VL. Further development of the Norbeck Social Support Questionnaire: Normative data and validity testing. Nursing Research. 1983; 32(1):4-9. [PubMed: 6549842]

107. Byers PH, Mullis MR. Reliability and validity of the Norbeck Social Support Questionnaire in psychiatric inpatients. Educational and Psychological Measurement. 1987; 47(2):445-448.

108. Norbeck, JS. Social support. In: Fitzpatrick, JJ.; Taunton, RL.; Benoliel, JQ., editors. Annual Review of Nursing Research. New York, NY: Springer; 1988. p. 85-109.

109. Dennis, ML.; Titus, JC.; White, MK., et al. Global Appraisal of Individual Needs: Administration Guide for the GAIN and Related Measures. Bloomington, IL: Chestnut Health Systems; 2003.

110. Buchan BJ, Dennis LM, Tims FM, et al. Cannabis use: Consistency and validity of self-report, on-site urine testing and laboratory testing. Addiction. 2002; 97(1):98-108. [PubMed: 12460132]

111. Dennis ML, Funk R, Godley SH, et al. Cross-validation of the alcohol and cannabis use measures in the Global Appraisal of Individual Needs (GAIN) and Timeline Followback (TLFB; form 90) among adolescents in substance abuse treatment. Addiction. 2004; 99(2):120-128. [PubMed: 15488110]

112. Godley MD, Kahn JH, Dennis ML, et al. The stability and impact of environmental factors on substance use and problems after adolescent outpatient treatment for cannabis abuse or dependence. Psychology of Addictive Behaviors. 2005; 19(1):62-70. [PubMed: 15783279]

113. Dennis ML, Chan Y, Funk RR. Development and validation of the GAIN Short Screener (GSS) for internalizing, externalizing and substance use disorders and crime/violence problems among adolescents and adults. The American Journal on Addictions. 2006; 15(1):80-91. [PubMed: 17182423]

114. Carter O, Pannekoek L, Fursland A, Allen KL, Lampard AM, Byrne SM. Increased wait-list time predicts dropout from outpatient enhanced cognitive behaviour therapy (CBT-E) for eating disorders. Behaviour Research and Therapy. 2012; 50(7-8):487-492. [PubMed: 22659158]

115. Parsons JT, Golub SA, Rosof E, Holder C. Motivational interviewing and cognitive-behavioral intervention to improve HIV medication adherence among hazardous drinkers: A randomized controlled trial. Journal of Acquired Immune Deficiency Syndrome. 2007; 46 (4):443-450.

116. Simpson HB, Maher MJ, Wang Y, Bao Y, Foa EB, Franklin M. Patient adherence predicts outcome from cognitive behavioral therapy in obsessive-compulsive disorder. Journal of Consulting and Clinical Psychology. 2011; 79(2):247-252. [PubMed: 21355639]

117. Edlund MJ, Wang PS, Berglund PA, et al. Dropping out of mental health treatment: patterns and predictors among epidemiological survey respondents in the United States and Ontario. American Journal of Psychiatry. 2002; 159(5):845-851. [PubMed: 11986140] 
118. Olfson M, Marcus SC, Druss B, et al. National trends in the use of outpatient psychotherapy. American Journal of Psychiatry. 2002; 159(11):1914-1920. [PubMed: 12411228]

119. van Minnen A, Arntz A, Keijsers GP. Prolonged exposure in patients with chronic PTSD: Predictors of treatment outcome and dropout. Behaviour Research and Therapy. 2002; 40(4): 439-457. [PubMed: 12002900]

120. Waghorn G, Chant D, Harris M. The stability of correlates of labour force activity. Acta Psychiatrica Scandinavica. 2009; 119(5):393-405. [PubMed: 19053967] 


\section{Table 1}

\section{Definitions of discharge reasons}

\section{Therapist and Supervisor can Select only 1:}

\section{Finished Full Treatment}

1 Treatment Completed with all goals met and sustainable- The client was discharged based on the mutual agreement of the team and client. All treatment goals were met and were sustainable.

2 Treatment Completed with majority of goals met and sustainable - The client was discharged based on the mutual agreement of the team and client. More than $65 \%$ of goals were met and were sustainable.

\section{Incomplete Treatment}

3 Administrative removal/withdrawal: Young adult was removed from the program by the MST program administration due to administrative issues or decisions unrelated to the progress of the case.

4 Restrictive Placement: The young adult was placed in a restrictive setting (detention center, residential placement) for a duration of time that precluded further MST involvement.

5 Placement, prior event: The young adult was placed in a restrictive setting (detention center, residential placement) due to an event or offense that occurred prior to the beginning of MST treatment.

6 Funding/referral source administrative removal/withdrawal: Young adult was removed from the program by the funding or referral source due to administrative issues or decisions unrelated to the progress of the case.

7 Moved: The young adult moved out of the program's service area.

8 Client explicit ending - Team decision to discharge due to client stated desire to end or stated lack of willingness to continue.

9 Client indirect ending - Decision to discharge client because team was not able to engage the client in treatment, despite persistence on the therapist's part to engage and align with the client.

10 Team directed ending - Team decision to discharge the client for reasons other than \#9.

11 Mutually initiated ending - Team and client both agreed that further progress was unlikely at this point and treatment would end, though not all treatment goals had been met or were not all sustainable (i.e. mutual judgment that further treatment would produce diminishing returns). 
Table 2

Demographics and significant history of study participants

\begin{tabular}{|c|c|}
\hline Variable & $\%(\mathrm{~N}=\mathbf{4 1})$ \\
\hline Male & 71 \\
\hline \multicolumn{2}{|l|}{ Age at Study Enrollment } \\
\hline $16^{*}$ & 2 \\
\hline 17 & 44 \\
\hline 18 & 42 \\
\hline 19 & 7 \\
\hline 20 & 5 \\
\hline \multicolumn{2}{|l|}{ Race } \\
\hline Black/African American & 44 \\
\hline Asian & 17 \\
\hline White/Caucasian & 32 \\
\hline Bi-Racial & 5 \\
\hline Other & 2 \\
\hline Hispanic & 20 \\
\hline Ever homeless & 15 \\
\hline Psychiatric hospitalization ever & 56 \\
\hline Substance abuse hospitalization ever & 15 \\
\hline Juvenile detention ever & 61 \\
\hline Jail/prison ever & 39 \\
\hline \multicolumn{2}{|l|}{ Primary residence past $12 \mathrm{MO}$} \\
\hline In your own apartment or home & 39 \\
\hline In your family's home & 44 \\
\hline In your girlfriend's or boyfriend's or spouse's home & 5 \\
\hline In another friend's home & 2 \\
\hline In a hospital or treatment facility for mental health problems & 5 \\
\hline In a boot camp, detention center, prison or jail for juveniles & 5 \\
\hline Ever employed & 71 \\
\hline \multicolumn{2}{|l|}{ Highest Education $^{* *}$} \\
\hline$<9^{\text {th }}$ grade & 13 \\
\hline $9^{\text {th }}$ grade & 8 \\
\hline $10^{\text {th }}$ grade & 38 \\
\hline $11^{\text {th }}$ grade & 33 \\
\hline High school completion or Graduate Equivalent Diploma & 8 \\
\hline \multicolumn{2}{|l|}{ Referral Source } \\
\hline Criminal Justice (probation, corrections) & 56 \\
\hline Juvenile Justice (detention, parole) & 20 \\
\hline
\end{tabular}

J Behav Health Serv Res. Author manuscript; available in PMC 2016 April 01. 


\begin{tabular}{|l|c|}
\hline Variable & \% (N=41) \\
\hline Child Welfare & 20 \\
\hline Other & 4 \\
\hline Level of Functioning (SF-36; Median, range) & $45,18-100$ \\
\hline Study Protocol & \\
\hline Phase 1 & 39 \\
\hline Phase 2 & 61 \\
\hline
\end{tabular}

* Participant began treatment at age 17 , but was enrolled in the study $<17^{\text {th }}$ birthday **

$n=24$ 
Table 3

Ultimate and instrumental outcomes among participants receiving MST-EA intervention

\begin{tabular}{|c|c|c|c|c|}
\hline Variable & Pre & Post & Statistic & p-value \\
\hline \multicolumn{5}{|c|}{ Ultimate Outcomes } \\
\hline Number of mental health symptoms $(\mathrm{N}=35)$ Median (Range) & $20(1-48)$ & $6(0-48)$ & $-3.9^{1}$ & $<.001$ \\
\hline Arrested $(\mathrm{N}=41)$ & $29 \%$ & $12 \%$ & $2.1(\mathrm{df}=1)^{2}$ & $>.10$ \\
\hline Number of Charges/Person (N=41) Median (Range & $0(0-9)$ & $0(0-5)$ & $-2.6^{1}$ & $<.01$ \\
\hline \multicolumn{5}{|c|}{ Instrumental Outcomes } \\
\hline Peer Delinquency (N=32) Median (Range) & $35(19-79)$ & $23.7(19-69)$ & $-2.1^{l}$ & $<.05$ \\
\hline Average Emotional Support (N=37) Median (Range) & $3.5(1.0-15.5)$ & $3.8(0.0-16.0)$ & $1.1^{1}$ & $>.10$ \\
\hline Average Instrumental Support (N=37) Median (Range) & $3.5(0.5-22.3)$ & $3.7(0.0-24.0)$ & $1.4^{1}$ & $>.10$ \\
\hline$\%$ Working $(\mathrm{N}=37)^{* *}$ & $13 \%$ & $27 \%$ & $1.8(\mathrm{df}=1)^{2}$ & $>.10$ \\
\hline Original Coaching $(\mathrm{N}=14)$ & $14 \%$ & $28 \%$ & $0.6(\mathrm{df}=1)^{2}$ & $>.10$ \\
\hline Vocational Coaching (N=13) & $8 \%$ & $23 \%$ & $0.3(\mathrm{df}=1)^{2}$ & $>.10$ \\
\hline Non-Vocational Coaching $(\mathrm{N}=10)$ & $20 \%$ & $30 \%$ & $0.0(\mathrm{df}=1)^{2}$ & $>.10$ \\
\hline$\%$ In School/Training (N=37) & $65 \%$ & $51 \%$ & $1.8(\mathrm{df}=1)^{2}$ & $>.10$ \\
\hline$\%$ In School/Training or Working ( $\mathrm{N}=37)$ & $70 \%$ & $73 \%$ & $0.0(\mathrm{df}=1)^{2}$ & $>.10$ \\
\hline \multicolumn{5}{|l|}{ Residence $(\mathrm{N}=37)$} \\
\hline$\%$ Living in Out-of-home setting ${ }^{*}$ & $27 \%$ & $11 \%$ & $2.1(\mathrm{df}=1)^{2}$ & $>.10$ \\
\hline$\%$ Living with family & $65 \%$ & $70 \%$ & $0.1(\mathrm{df}=1)^{2}$ & $>.10$ \\
\hline$\%$ Living on own or with peers & $22 \%$ & $24 \%$ & $0.0(\mathrm{df}=1)^{2}$ & $>.10$ \\
\hline \multicolumn{5}{|l|}{ Substance Use } \\
\hline GAIN Substance Problem Scale ${ }^{\dagger}(\mathrm{N}=31)$ Median (Range) & $2(0-14)$ & $0(0-11)$ & $-1.6^{1}$ & $>.10$ \\
\hline \multicolumn{2}{|l|}{ Related Samples Wilcoxon, } & \multicolumn{3}{|c|}{2 Related Samples McNemar } \\
\hline
\end{tabular}

J Behav Health Serv Res. Author manuscript; available in PMC 2016 April 01. 